\title{
PENGARUH KEHARMONISAN KELUARGA DAN LINGKUNGAN SOSIAL SEKOLAH TERHADAP VANDALISME REMAJA SMP NEGERI 14 PONTIANAK
}

\author{
Muliyani, Yohanes Bahari, Rustiyarso \\ SMPN 14 Pontianak \\ Email: muliyanilian414@gmail.com
}

\begin{abstract}
This study aims to determine the interaction of family and social environment on the vandalism behavior of eighth grade students of SMP Negeri 14 Pontianak. This research method is quantitative with a research sample of 110 VIII students using purposive sampling. Data was taken using a questionnaire. The results showed that vandalism was low at $60.8 \%$, family harmony was $44.7 \%$ and the school environment was categorized as very high at $34.4 \%$. The results of the test show Fcount $(31,328)>$ Ftable (3.08) and a significance of $0.00<0.05$, meaning that family harmony and social environment have a significant effect on vandalism behavior. tcount of the decent family harmony variable $-4.486>$ ttable 1.982 with a significance of $0.00<0.05$, which means that there is a significant negative effect. tcount of the appropriate school social environment variable $-2.547>$ ttable 1.982 with a significance of $0.01<0.05$, which means that there is a significant negative effect. Regression equation $Y^{\prime}=68.074+(-$ $0.418)+(-0.313)+e$. The determinant value of Adjusted $R 2=0.358$, which means that the influence of family interaction and social environment on vandalism behavior is low, namely $35.8 \%$.
\end{abstract}

\section{Keywords: Harmonious Family, School Social Environment, Vandalism.}

\section{PENDAHULUAN}

Masyarakat tentu mengharapkan remaja bisa menjadi agen perubahan yang dapat diandalkan serta taat pada nilai dan norma yang berlaku di dalamnya. Namun pada kenyataan, remaja seringkali kesulitan untuk menyesuaikan diri di lingkungan sosialnya sehingga dalam proses pencarian jati diri remaja seringkali terjebak dalam perilaku menyimpang. Penyimpangan sosial yang dilakukan remaja biasanya dimaksudkan untuk mendapatkan pengakuan dari masyarakat atau orang terdekat seperti keluarga dan temanteman sebaya. Banyak sekali bentuk menyimpang sosial yang sering terjadi di kalangan remaja salah satu contoh adalah perilaku vandalisme.

Secara sosiologis, vandalisme dapat dikatakan sebagai salah satu wujud dari patologi sosial karena termasuk tindakan yang merugikan dan dapat digolongkan sebagai sebuah tindakan kriminal.

Pelaku aksi vandalisme berasal dari kalangan remaja di sekitar lingkungan sekolah yang putus sekolah. Ditemukan bahwa pelaku vandalisme ternyata tidak hanya berasal dari kalangan remaja yang putus sekolah, karena pada kenyataanya remaja yang bersekolah pun seringkali melakukan tindakan vandalisme. Seperti yang dikutip dari penelitian Corene de Wet (2004, p. 206) berikut ini:

"Learners, particularly boys between the ages of 14 and 19, are the most important vandals. However, it is clear that schools are regularly vandalised by herdsmen, gangsters, drop-outs, ex lerarners, and learners from neighbouring schools. The research indicated that juridical, economic drug and alcohol, as well as learner - related, problems are 


\section{considered important couses of school vandalism"}

Berdasarkan hasil penelitian de Wet di atas, diketahui bahwa pelaku vandalisme cenderung terjadi pada remaja dengan rentang umur 14-19 tahun baik yang putus sekolah maupun yang masih bersekolah.

Adapun perilaku vandalisme di sekolah seperti yang dikatakan Bloemhoff (Cummins 2003, p.p 1-2) bahwa "pelaku vandalisme di sekolah melakukan perusakan terutama memecahkan jendela menggambar grafiti, menyebabkan kerusakan ruangan antara lain ruang kelas, kamar kecil, furnitur dan buku serta peralatan dan lapangan olahraga".

Kenyataan ini sangat disayangkan karena bagaimanapun lingkungan sekolah adalah salah satu faktor penunjang dalam keberhasilan belajar, namun dengan maraknya perilaku vandalisme siswa di sekolah dapat menghambat proses pembelajaran kenyaman belajar. Seperti yang dikatakan Perry (Zuzile, 2003, p. 1), "Vandalism can couse teaching and learning to collapse as school programmes must often be interrupted in order to repair vandalised structures". Tempat dan lingkungan belajar yang nyaman akan memudahkan siswa untuk berkonsentrasi. Lingkungan yang nayaman dan ditunjang dengan fasilitas yang lengkap akan menjadikan remaja lebih menikmati proses belajar di sekolah sehingga akan mendapatkan hasil belajar yang lebih baik.

Menurut Cummins (2003, p. 1), alasan perusakan sekolah sangat kompleks dan beragam. Masa remaja ditandai oleh kecintaan akan petualangan, pencarian kegembiraan, dankebutuhan untuk menemukan hal-hal baru dan identitas diri sendiri. Pendapat tersebut sejalan dengan pendapat Black (2002, p. 2) yaitu sebagai berikut:

"The reasons for school vandalism are complex and vareid. Adolescence is characterised by the love of adventure, a search for excitement, and the need to discover new things and one's own identity. Vandalismis consequently not always committed with the exclusive purpose of causing damage, but rather for excitement and pleasure, as well as a search for identity and acceptance"

Menurut Theron (1991, p. 49), faktor yang berkaitan dengan vandalisme di sekolah terdiri dari faktor internal yang berkaitan dengan perasaan siswa seperti emosi, rasa ingin diakui akan identitas mereka serta kurangnya kasih sayang dan perhatian dari keluarga. Sedangkan berdasarkan faktor eksternal yang berkaitan dengan pengaruh teman sebaya.

Ani Safitri dalam Masruri, K. (2011, p. 19) menyatakan bahwa hal-hal yang menjadi faktor penyebab perilaku vandalisme antara lain adalah: (1) pengaruh rekan sebaya, (2) pengaruh orang tua dan keluarga, (3) pengaruh media masa, dan (4) pengaruh lingkungan masyarakat.

Keluarga merupakan agen sosialisasi pertama bagi anak. Keluarga memiliki fungsifungsi yang harus dijalankan agar menjadi keluarga yang harmonis. Keluarga yang harmonis menjadi tempat remaja memperoleh perhatian yang diperlukan untuk perkembangan jiwanya. Maka dari itu keharmonisan keluarga diduga kuat sebagai salah satu faktor yang mempengaruhi perilaku remaja.

Menurut de Wet (2004), terdapat hubungan yang signifikan atara ketidakcocokan orang tua dan perilaku menyimpang. Semakin tinggi ketidakkonsistenan orang tua, maka semakin cenderung anak berperilaku vandalistik. Selain itu, penelitian yang dilakukan oleh de Wet (2004, p. 206) juga mengungkapkan bahwa orang yang memiliki nilai rata-rata lebih rendah dibandingkan orang yang memiliki nilai rata-rata tinggi lebih rentan untuk melakukan sabotase dan perilaku vandalistik, sehingga lingkungan sekolah juga diduga kuat sebagai faktor yang mempengaruhi perilaku vandalisme remaja di sekolah.

Sekolah merupakan lingkungan yang sangat akrab bagi remaja karena di sekolah meraka melakukan proses sosialisasi bersama teman sebaya dan para guru serta warga sekolah lainnya yang akan membentuk karakter remaja. Pendidik harus memainkan 
peran utama dalam memerangi vandalisme peserta didik, karena mereka tidak hanya memiliki akses ke peserta didik selama tahuntahun penting pembentukan mereka, tetapi juga seringkali merukan satu-satunya faktor konservatif dalam kehidupan pemuda yang tumbuh di rumah atau lingkungan di mana kejahatan berkuasa.

Pada tanggal 10 Agustus 2020, peneliti melakukan pengamatan pada lingkungan sekolah dan wawancara singkat dengan Bapak Yusuf selaku koordinator bidang sarana dan prasarana SMP Negeri 14 Pontianak mengenai fenomena perilaku vandalisme yang terjadi di SMP Negeri 14 Pontianak. Berikut ini adalah contoh jejak vandalisme yang ditemukan di SMP Negeri 14 Pontianak sebagai berikut:

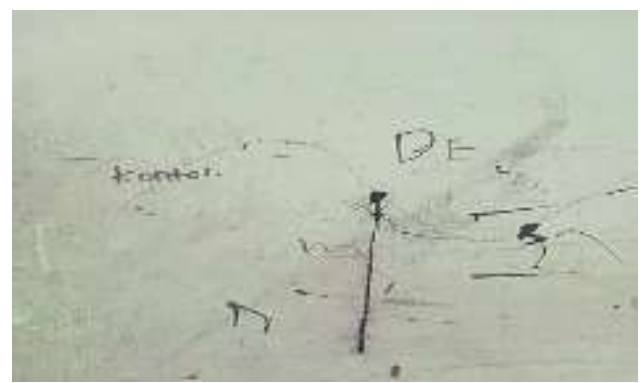

Gambar 1. Coretan di dinding kelas

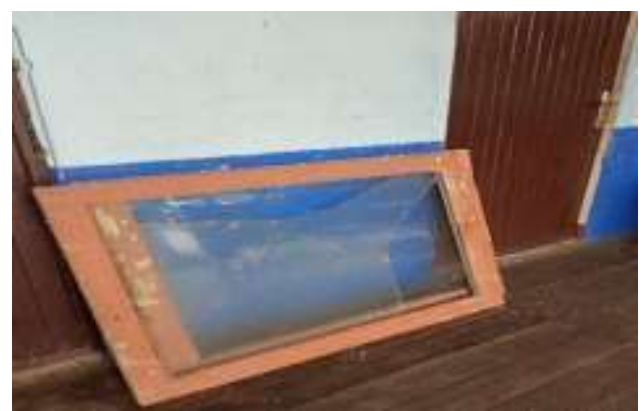

\section{Gambar 2. Jendela kelas yang pecah}

Selain yang terlihat pada gambar di atas, peneliti juga menemukan banyaknya coretan di meja, kursi dan dinding kelas maupun dinding toilet sekolah sebagai indikasi adanya perilaku vandalisme di SMP Negeri 14 Pontianak. maka dari itu, peneliti tertarik meneliti bagaimana perilaku vandalisme siswa di sekolah, dan bagaimana pengaruh keharmonisan keluarga dan lingkungan sosial sekolah terhadap perilaku vandalisme siswa kelas VIII SMP Negeri 14 Pontianak.

\section{METODE PENELITIAN}

Penelitian ini menggunakan pendekatan kuantitatif untuk mengkaji tentang pengaruh keharmonisan keluarga dan lingkungan sekolah terhadap perilaku vandalisme remaja di sekolah. Remaja yang menjadi subjek penelitian adalah siswa-siswi yang bersekolah di SMP Negeri 14 Pontianak. Penelitian ini dirancang untuk menentukan sebarapa besar pengaruh variabel independen (keharmonisan keluarga dan lingkungan sekolah) terhadap variabel dependen (perilaku vandalisme di sekolah).

Siswa-siswi kelas VIII dipilih menjadi populasi dalam penelitian ini dikarenakan siswa kelas VII adalah siswa yang baru diterima di SMP Negeri 14 tahun ajaran 2020/2021, belum memiliki pengalaman melakukan pembelajaran tatap muka di SMP Negeri 14 Pontianak yang disebabkan adanya pandemi Covid-19 yang masih belum memungkinkan siswa masuk sekolah. Sedangkan siswa kelas IX tidak memungkinkan untuk diteliti karena sudah menerima surat kelulusan dari sekolah. Maka yang menjadi populasi pada penelitian ini adalah siswa-siswi yang berada di kelas VIII yang sudah mengisi angket survey oleh peneliti dan menjawab pernah melakukan vandalisme yaitu berjumlah 233 siswa, yang terdiri dari orang siswa dan orang siswi.

Peneliti menarik sampel dengan purposive sampling yaitu teknik pengambilan sampel berdasarkan kriteria-kriteria tertentu sesuai dengan masalah penelitian. Siswa yang dapat dijadikan sampel adalah siswa yang terindikasi melakukan perilaku vandalisme selama bersekolah di SMP Negeri 14 Pontianak dalam kategori cenderung tinggi.

Penelitian ini akan dilaksanakan di SMP Negeri 14 Pontianak yang beralamat di Jalan Tani 1, Kelurahan Saigon, Kecamatan Pontianak Timur, Kalimantan Barat. Adapun waktu penelitian akan dilakukan pada semester 1 tahun ajaran 2020/2021.

Peneliti mengumpulkan data dari lapangan dengan menggunakan sebuah teknik pengumpulan data secara tidak langsung yaitu kuesioner. Peneliti membagikan kuesioner melalui media google form kepada sampel 
penelitian yaitu siswa kelas VIII yang terpilih menjadi sampel dengan jumlah 110 siswa, yang terdiri dari $47 \%$ siswa dan $53 \%$ siswi, untuk menggali informasi tentang perilaku vandalisme remaja di SMP Negeri 14 Pontianak.

Penelitian ini menggunakan kusioner sebagai alat untuk mengumpulkan data. Kuesioner yang dibuat berbentuk pilihan ganda yang menggunakan skala likert dengan membagi soal positif dan negatif. Adapun untuk mengukur validitas instrumen, peneliti memilih untuk menggunakan analisis validitas konstruk. Hasil test reliabilitas menyatakan variabel perilaku vandalisme memperoleh koefisien Alpha sebesar 0,725, variabel keharmonisan keluarga sebesar 0,761 dan lingkungan sosial sekolah memperoleh hasil 0,752 yang berarti instrumen dari ketiga variabel memiliki reliabilitas yang tinggi.

Analisis data yang dilakukan melewati uji syarat analisis terlebih dahulu yaitu uji normalitas, uji linieritas, uji multikolinieritas, dan uji heteroskedastisitas. Setelah itu peneliti menguji hipotesis secara simultan dan parsial dan melakukan analisis regresi berganda serta melakukan uji koefisien determinasi untuk mengetahui seberapa besar pengaruh variabel bebas terhadap variabel terikat.

\section{HASIL PENELITIAN DAN PEMBAHASAN \\ Hasil \\ Perilaku Vandalisme Siswa}

Sebanyak 248 siswa yang mengisi angket survey terdapat hasil bahwa terdapat 110 siswa yang melakukan perilaku vandalisme dengan berkategori tinggi. Sampel terpilih terdiri dari 52 siswa dan 58 siswi. Maka dari itu dapat dikatakan bahwa vandalisme yang terjadi di SMP Negeri 14 Pontianak 53\% dilakukan oleh murid perempuan dan $47 \%$ dilakukan oleh murid laki-laki.

Rata-rata skor jawaban responden berada pada nilai 334, yang jika dilihat dari rentang skor yang diperoleh maka skala perilaku vandalisme siswa kelas VIII SMP Negeri 14 Pontianak berada pada 287 - 374 yang berarti cukup tinggi.

Perilaku vandalisme siswa dapat dilihat dari tabel berikut:

Tabel 1. Persentase Perilaku Vandalisme Siswa

\begin{tabular}{llcccc}
\hline No & $\begin{array}{c}\text { Perilaku } \\
\text { Vandalisme }\end{array}$ & Jumlah Item & $\begin{array}{c}\text { Jumlah skor } \\
\text { Jawaban } \\
\text { Responden }\end{array}$ & Skor ideal & Persentase \\
\hline 1 & Graffiti & 3 & 1261 & 1650 & $76,4 \%$ \\
\hline 2 & Cutting & 3 & 1010 & 1650 & $61,2 \%$ \\
\hline 3 & Pluking & 3 & 753 & 1650 & $45,6 \%$ \\
\hline 4 & Taking & 3 & 866 & 1650 & $52,5 \%$ \\
\hline 5 & Destroying & 3 & 1126 & 1650 & $68,2 \%$ \\
\hline
\end{tabular}

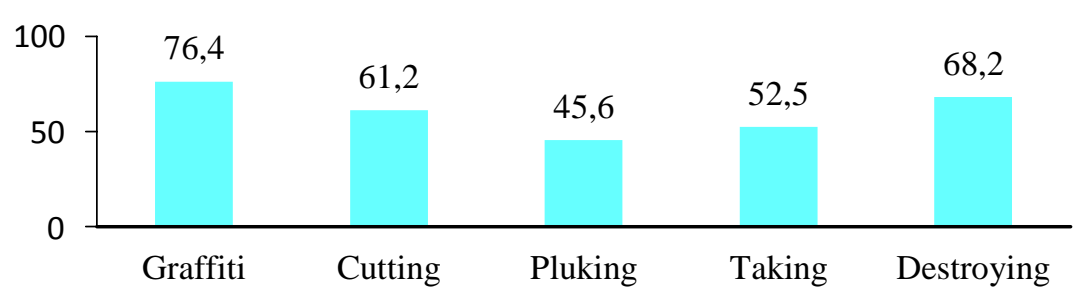

Gambar 3. Perilaku Vandalisme Siswa

Berdasarkan tabel 1 di atas, dapat dilihat bahwa ciri perilaku vandalisme yang paling banyak ditemukan adalah graffiti dengan hasil $76,4 \%$ sedangkan perilaku 
vandalisme terendah adalah pluking yaitu hanya sebesar 45,6\% dan termasuk kategori cukup tinggi.

\section{Keharmonisan Keluarga}

Data keharmonisan keluarga siswa adalah skor yang diperoleh dari jawaban 110 siswa kelas VIII SMP Negeri 14 Pontianak sebagai sampel yang telah dipilih melalui teknik purposive sampling. Adapun 110 siswa tersebut sebelumnya terdata sebagai siswa yang cenderung melakukan perilakku vandalisme dengan kategori tinggi. Berdasarkan perhitungan skala jawaban responden adalah sebesar 245,7 yang berada pada rentang 199-286 yang berarti keharmonisan keluarga pada siswa yang melakukan vandalisme berkategori rendah.

Tabel 2. Persentase Keharmonisan Keluarga Siswa

\begin{tabular}{llcccc}
\hline No & Indikator Keharmonisan Keluarga & $\begin{array}{c}\text { Jumlah } \\
\text { Item }\end{array}$ & $\begin{array}{c}\text { Jumlah skor } \\
\text { Jawaban } \\
\text { Responden }\end{array}$ & Skor ideal & Persentase \\
\hline 1 & Rasa kasih sayang & 3 & 771 & 1650 & $46,7 \%$ \\
\hline 2 & Saling pengertian & 3 & 721 & 1650 & $43,7 \%$ \\
\hline 3 & Komunikasi efektif & 3 & 724 & 1650 & $43,9 \%$ \\
\hline 4 & Punya waktu berkumpul bersama & 3 & 712 & 1650 & $43,2 \%$ \\
\hline 5 & Kerjasama & 3 & 758 & 1650 & $45,9 \%$ \\
\hline
\end{tabular}

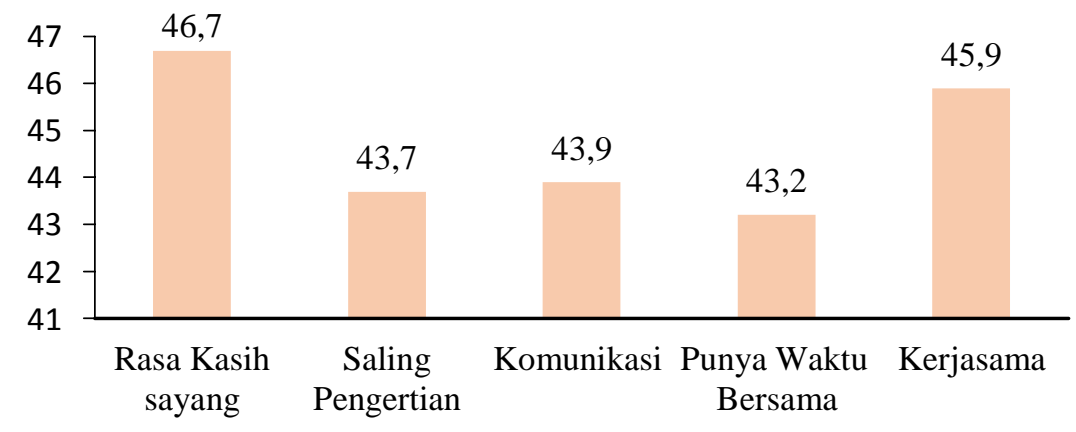

\section{Gambar 4. Keharmonisan Keluarga Siswa}

Secara lebih rinci, gambaran mengenai keharmonisan keluarga siswa yang melakukan vandalisme di sekolah mendapatkan hasil bahwa $45 \%$ diamana indikator yang memiliki persentase paling tinggi diantara kelima indikator keharmonisan keluarga adalah adanya rasa kasih sayang di dalam keluarga siswa yang melakukan vandalisme semetara itu indikator yang mendapatkan persentase paling rendah ialah adanya waktu berkumpul bersama dalam keluarga.

\section{Lingkungan Sosial Sekolah}

Rata-rata skor jawaban adalah 198 yang berada pada rentang 110-198 yang berarti lingkungan sosial sekolah pada siswa yang melakukan vandalisme di kelas VIII SMP Negeri 14 Pontianak berkategori sangat rendah.

Diantara ketiga indikator variabel lingkungan sosial sekolah, persentase tertinggi adalah hubungan siswa dengan teman sebaya yaitu sebesar $38,8 \%$ dan indikator dengan persentase terendah yaitu hubungan siswa dengan guru yaitu 34,3\%, sehingga dapat dikatakan bahwa lingkungan sosial sekolah pada siswa yang melakukan vandalisme di kelas VIII SMP Negeri 14 Pontianak berkategori rendah. 
Tabel 3. Persentase Lingkungan Sosial Sekolah Siswa

\begin{tabular}{llcccc}
\hline No & $\begin{array}{c}\text { Indikator Lingkungan Sosial } \\
\text { Sekolah Siswa }\end{array}$ & $\begin{array}{c}\text { Jumlah } \\
\text { Item }\end{array}$ & $\begin{array}{c}\text { Jumlah skor } \\
\text { Jawaban } \\
\text { Responden }\end{array}$ & Skor ideal & Persentase \\
\hline 1 & Hubungan siswa dengan guru & 5 & 943 & 2750 & $34,3 \%$ \\
\hline 2 & $\begin{array}{l}\text { Hubungan siswa dengan teman } \\
\text { sebaya }\end{array}$ & 5 & 1066 & 2750 & $38,8 \%$ \\
\hline 3 & $\begin{array}{l}\text { Hubungan siswa dengan warga } \\
\text { dan peraturan sekolah. }\end{array}$ & 5 & 960 & 2750 & $34,9 \%$ \\
\hline
\end{tabular}

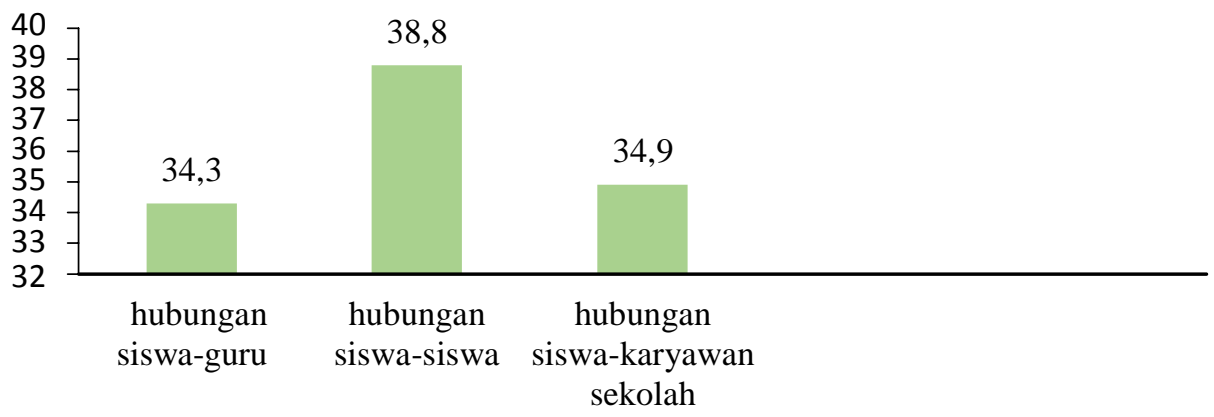

\section{Gambar 5. Lingkungan Sosial Sekolah}

\section{Uji Hipotesis dan Regresi Uji Simultan (F)}

Uji simultan dilakukan untuk mengetahui ada atau tidaknya pengaruh variabel keharmonisan keluarga dan lingkungan sosial sekolah secara bersamasama terhadap perilaku vandalisme siswa kelas VIII di SMP Negeri 14 Pontianak. Hasil uji simultan pada penelitian ini dapat dilihat $\mathrm{F}_{\text {hitung }}>\mathrm{F}_{\text {tabel }}$ yaitu $31,328>3,08$ dengan signifikansi $0,00<0,05$ yang berarti hipotesis alternatif pertama (Ha-1) yang berbunyi "keharmonisan keluarga dan lingkungan sosial sekolah berpengaruh signifikan terhadap perilaku vandalisme siswa kelas VIII di SMP Negeri 14 Pontianak" dapat diterima dan $\mathrm{H} 0-1$ ditolak.

\section{Uji Parsial (t)}

Uji parsial atau uji t dimaksudkan untuk mengetahui bagaimana pengaruh keharmonisan keluarga terhadap perilaku vandalisme siswa dan bagaimana pengaruh lingkungan sosial sekolah terhadap perilaku vandalisme siswa secara sendiri-sendiri. diketahui bahwa nilai $t_{\text {hitung }}$ variabel keharmonisan keluarga > nilai $t_{\text {tabel }}$ yaitu $4,486>1,982$. Hasil menunjukkan $t_{\text {hitung }}$ pada variabel keharmonisan keluarga bernilai negatif dan nilai signifikansi $0.00<$ 0.05 yang berarti terdapat pengaruh signifikan negatif pada keharmonisan keluarga terhadap perilaku vandalisme siswa kelas VIII di SMP Negeri 14 Pontianak. Kesimpulannya adalah hipotesis alternatif kedua (Ha-2) diterima dan $\mathrm{H} 0-2$ ditolak.

Hasil uji t pada variabel lingkungan sosial sekolah juga tercantum dalam tabel 4.16. Diketahui bahwa nilai $t_{\text {hitung }}$ variabel lingkungan sosial sekolah $>$ nilai $t_{\text {tabel }}$ yaitu $2,547>1,982$. Hasil menunjukkan $t_{\text {hitung }}$ pada variabel lingkungan sosial sekolah bernilai negatif dan nilai signifikansi $0.01<$ 0.05 yang berarti terdapat pengaruh signifikan negatif pada lingkungan sosial sekolah terhadap perilaku vandalisme siswa kelas VIII di SMP Negeri 14 Pontianak. 
Kesimpulannya adalah hipotesis alternatif kedua (Ha-3) diterima dan $\mathrm{H} 0-3$ ditolak.

\section{Analisis Regresi Berganda}

Analisis dilakukan dengan

menggunakan bantuan program SPSS 20.0 ver. Analisis yang dilakukan selanjutnya adalah mengetahui bagaimana variabel bebas dapat mempengaruhi naik turunnya variabel terikat. Persamaan regresi sebagai berikut:

$\mathrm{Y}^{\prime}=\mathrm{a}+\mathrm{b}_{1} \mathrm{X}_{1}+\mathrm{b}_{2} \mathrm{X}_{2}+\mathrm{e}$

$\mathrm{Y}^{\prime}=68,074+(-0,418)+(-0,313)+\mathrm{e}$

Berdasarkan persamaan regresi di atas dapat diartikan bahwa jika variabel lingkungan sosial sekolah tetap dan keharmonisan keluarga ditingkatkan sebesar 1 maka perilaku vandalisme akan menurun sebesar 0,418 dan apabila keharmonisan keluarga tetap sedangkan variabel lingkungan sosial sekolah ditingkatkan 1 maka perilaku vandalisme akan berkurang -0,313. Hasil penelitian menghasilkan regresi negatif pada variabel keharmonisan keluarga dan lingkungan sosial sekolah terhadap perilaku vandalisme.

Dengan demikian maka dapat disimpulkan bahwa jika siswa memiliki keluarga yang harmonis dan lingkungan sosial sekolah yang baik, maka kecenderungan perilaku vandalisme oleh siswa akan berkurang dan sebaliknya. Perilaku vandalisme siswa dapat diprediksi oleh tingkat keharmonisan keluarga dan lingkungan sosial sekolah pada siswa tersebut. Semakin baik tingkat keharmonisan keluarga dan lingkungan sosial sekolah maka perilaku vandalisme siswa semakin berkurang.

\section{Koefisien Determinasi}

Uji koefisien determinasi pada penelitian ini dimaksudkan untuk melihat besaran pengaruh keharmonisan keluarga dan lingkungan sosial sekolah terhadap perilaku vandalisme siswa kelas VIII di SMP Negeri 14 Pontianak.

Besarnya koefisien Adjusted $R$ square adalah 0,358 yang berarti keharmonisan keluarga dan lingkungan sosial siswa secara bersama-sama dapat memprediksi perilaku vandalisme sebesar $35,8 \%$, sedangkan $64,2 \%$ sisanya dipengaruhi oleh variabel lain yang tidak diteliti pada penelitian ini.

Adapun sumbangan pengaruh dari masingmasing variabel bebas terhadap variabel terikat dapat dilihat dari perhitungan sebagai berikut:

$$
\begin{array}{ll}
\text { Variabel X } & =\text { Beta } \times \text { Zero order } \\
\mathrm{X} 1 & =-0,430 \times-0,575=0,247 \\
\mathrm{X} 2 & =-0,244 \times-0,501=0,122
\end{array}
$$

Berdasarkan hasil perhitungan di atas, maka dapat disimpulkan bahwa keharmonisan keluarga menyumbang prediksi sebesar $24,7 \%$ dan lingkungan sosial sekolah menyumbang prediksi $12,2 \%$ terhadap perilaku vandalisme siswa. Jika dijumlahkan nilai dari kedua variabel bebas di atas, maka terdapat hasil 36,9\% yang berarti sumbangan dari kedua variabel bebas secara bersama-sama terhadap variabel terikat.

\section{Pembahasan}

Berdasarkan hasil penelitian yang telah dikemukakan sebelumnya, diketahui bahwa perilaku siswa yang melakukan vandalisme pada kelas VIII di SMP Negeri 14 Pontianak termasuk dalam kategori cukup tinggi yaitu dengan rata-rata skor jawaban adalah 334,4. Dimana perilaku tersebut $57 \%$ dilakukan oleh murid perempuan dan $43 \%$ dilakukan oleh murid laki-laki. Penelitian pada variabel perilaku vandalisme menunjukkan bahwa dari 5 perilaku vandalisme remaja yang dikemukakan oleh Lase (2003, p. 12), jika diurutkan maka perilaku vandalisme banyak dilakukan adalah graffity $76,4 \%$ dengan kategori tinggi, destroying sebesar 
$68,2 \%$ yang berarti tinggi, selanjutnya destroying sebesar $68,2 \%$ yang berarti tinggi, cutting sebesar $61,2 \%$ berkategori tinggi, taking $52,5 \%$ yang berarti cukup tinggi dan yang paling rendah adalah pluking yaitu 45,6\% dalam kategori cukup tinggi.

Berdasarkan hasil jawaban yang diperoleh, dapat digambarkan bahwa siswa kelas VIII di SMP 14 Pontianak kebanyakan melakukan perilaku vandalisme yaitu dengan mencoret-coret, atau menulis dan membuat gambar pada sarana dan prasarana sekolah. Hal ini berarti sesuai dengan temuan saat prariset dimana peneliti menemukan banyaknya tulisan dan coretan yang ditemukan pada meja, kursi, buku perpustakaan serta dinding kelas/toilet. Perilaku vandalisme yang paling banyak dilakukan selanjutnya adalah destroying, yaitu perilaku yang cenderung berakibat kerusakan pada fasilitas sekolah. Kerusakan yang dilakukan secara sadar dan tidak sadar, baik langsung maupun secara berangsur dapat ditemukan pada buku pelajaran yang dipinjamkan dari perpustakaan dan kaca jendela yang pecah yang diketahui dikarenakan ada siswa yang bermain bola di dalam kelas. Penemuan ini sejalan dengan Bloemhoff (Cummins 2003, p. 1-2) yang menemukan bahwa "pelaku vandalisme di sekolah melakukan perusakan terutama memecahkan jendela menggambar grafiti, menyebabkan kerusakan ruangan antara lain ruang kelas, kamar kecil, furnitur dan buku serta peralatan dan lapangan olahraga". Sementara itu, perilaku vandalisme yang presentase nya paling rendah adalah pluking yaitu kebiasaan memetik daun, tumbuhan, buah, pada tanaman di lingkungan sekolah. Artinya siswa yang melakukan vandalisme di kelas VIII SMP Negeri 14 Pontianak jarang melakukan perilaku vandalisme tersebut. $\begin{array}{cccc}\text { Hasil penelitian } & \text { ini } & \text { juga } \\ \text { menggambarkan bahwa siswa yang }\end{array}$ melakukan vandalisme sebenarnya memiliki keluarga yang berkategori kurang harmonis. Adapun indikator pada variabel keharmonisan keluarga jika diurutkan sampai yang terendah adalah komunikasi yang efektif yaitu sebesar $49,7 \%$ saling pengertian $43,7 \%$ dan yang paling rendah adalah waktu berkumpul bersama keluarga yaitu sebesar 43,2\%.

Analisis selanjutnya adalah tentang lingkungan sosial sekolah yang dirasakan oleh siswa yang melakukan vandalisme pada penelitian ini berada pada kategori sangat rendah yaitu sebesar $36 \%$. Jika diurutkan berdasarkan indikator maka hubungan siswa dengan guru termasuk pada kategori rendah yaitu $34,3 \%$, selanjutnya hubungan siswa dengan sistem di sekolah $34,9 \%$ dan yang paling tinggi dari ketiga indikator lingkungan sosial sekolah adalah hubungan siswa dengan teman sebayanya yang juga termasuk kategori rendah yaitu 38,8\%. Artinya siswa yang melakukan vandalisme di sekolah mengalami kesulitan dalam menyesuaikan diri pada lingkungan sosial di sekolahnya. Hal ini dapat terlihat pada jawaban angket siswa yang cenderung memiliki hubungan yang rendah kepada guru, teman, dan peraturan di sekolah. Jika hubungan siswa dengan guru termasuk rendah, artinya siswa tersebut merasa tidak nyaman saat proses pembelajaran, dan saat berkomunikasi dengan guru. Perasaan tidak nyaman tersebut juga dapat merambat pada kegagalan siswa dalam menyesuaikan diri dengan nilai dan norma yang diajarkan di sekolah. Sementara itu, siswa yang kurang beradaptasi dengan peraturan sekolah akan dianggap menyimpang dari konformitas dan dipandang negatif oleh teman-teman sebayanya sehingga muncul labeling pada 
siswa tersebut dan menyebabkan ia cenderung semakin melakukan perilaku menyimpang.

Beberapa penelitian sebelumnya tentang vandalisme menghasilkan jawaban bahwa vandalisme di sekolah lebih banyak dilakukan oleh murid laki-laki. Sementara pada penelitian ini menemukan hasil yang berbeda yaitu $53 \%$ vandalisme yang berkategori tinggi justru dilakukan oleh murid perempuan. Hasil penelitian Fuada (2011, p. 34) menyatakan bahwa murid lakilaki lebih banyak melakukan kenakalan yang berkaitan dengan kekerasan seperti memukul, berkelahi, tawuran, atau melawan guru secara terang-terangan. Sedangkan kenakalan yang dilakukan oleh murid perempuan tidak terlalu kentara. Perempuan melakukan kenakalan seperti membantah orang tua di rumah, pergi dari rumah tanpa pamit, dan membolos.

Berdasarkan penemuan tersebut, jika dikaitkan pada penelitian ini dapat dikatakan bahwa murid perempuan juga melakukan kenakalan dan perilaku menyimpang. Dalam penelitian ini, ditemukan bahwa murid perempuan melakukan vandalisme seperti mencoret-coret meja dan dinding toilet sekolah karena tindakan tersebut tidak mendapatkan perhatian khusus oleh guru maupun tata tertib di sekolah, sehingga mereka merasa lebih aman melakukan vandalisme daripada kenakalan lainnya yang akan menarik perhatian guru dan dikenai sanksi yang berat.

Berdasarkan uji asumsi yang meliputi uji normalitas, linieritas, multikolinieritas, dan heteroskedastisitas diketahui bahwa data keharmonisan keluarga dan lingkungan sosial sekolah berdistribusi normal, linier dan memenuhi syarat untuk melakukan penelitian regresi. Berdasarkan hasil pengujian hipotesis diketahui bahwa $\mathrm{f}_{\text {hitung }}$ yang bernilai 31,328 $>\mathrm{f}_{\text {tabel }} 3,08$ yang berarti

keharmonisan keluarga dan lingkungan sosial sekolah secara simultan berpengaruh signifikan terhadap perilaku vandaslisme siswa. Sehingga Ha diterima dan $\mathrm{H}_{0}$ ditolak. Hasil penelitian ini mengungkapkan bahwa semakin tinggi

keharmonisan keluarga dan lingkungan sosial sekolah maka semakin rendah pula tingkat perilaku vandalisme pada siswa, sebaliknya jika keharmonisan keluarga dan lingkungan soisal kurang, maka tingkat vandalisme akan bertambah walaupun dalam penelitian ini pengaruh dari keharmonisan keluarga dan lingkungan sosial siswa tegolong rendah yaitu $35,8 \%$.

Hasil temuan sejalan dengan pendapat Ani Safitri dalam Masruri, K. (2011, p. 9) yang mengungkapkan bahwa keluarga dan teman sebaya dapat berpengaruh pada sifat vandalisme dikalangan remaja. Menurut teori struktural fungsional, setiap sistem dalam kehidupan sosial saling terkait satu sama lain dan saling mempengaruhi. Adanya disfungsi dari satu komponen dapat menyebabkan rusaknya komponen lain. Dengan demikian, jika di dalam keluarga terdapat disfungsi peran dapat menyebabkan siswa melakukan perilaku menyimpang di sekolah termasuk contohnya yaitu perilaku vandalisme. Hal ini didukung oleh penemuan dari penelitian Fuada (2011, p. 36) yang menyatakan "bahwa siswa dengan tingkat kenakalan kategori rendah mendapatkan pengawasan, dukungan, dan perhatian dari keluarga khususunya orangtua. Sedangkan siswa dengan tingkat kenakalan kategori tinggi, sebaliknya". Menurut Santrock (2002), "Pengawasan, dukungan, dan perhatian tersebut merupakan salah satu cara mencegah siswa untuk bertindak nakal, terutama pemantuan 
orangtua atas keberadaan siswa yang bisa meramalkan tindakan kenakalan".

Keluarga sebagai agen sosialisasi utama bagi remaja harus melakukan kontrol sosial sehingga dapat mencegah adanya perilaku menyimpang yang dilakukan oleh anak di luar rumah. Adanya kontrol dapat dilakukan dengan cara membangun komunikasi yang positif dan rasa kasih sayang, serta adanya rasa saling pengertian diantara keluarga. Hal ini ditunjukkan dengan kebiasaan keluarga membangun diskusi antaranggota keluarga, dan menyempatkan diri untuk saling berkumpul bersama agar tercipta komunikasi yang efektif dalam keluarga sehingga dapat meminimalisir konflik dan rasa kesepian dalam keluarga.

Lingkungan sosial sekolah juga berpengaruh terhadap perilaku vandalisme siswa meskipun dalam penelitian ini pengaruh yang diberikan berada dalam kategori rendah yaitu $12,2 \%$. Sekolah merupakan rumah kedua bagi siswa. Dimana siswa menghabiskan setengah dari waktunya dalam sehari berada di lingkungan sekolah. Dengan demikian lingkungan sosial sekolah yang berupa hubungan dengan guru, teman, dan sistem manajemen sekolah mempengaruhi perilaku siswa. Seperti halnya keluarga, sekolah merupakan lembaga resmi tempat siswa mendapatkan sosialisasi dan terdapat kontrol sosial di dalamnya. Di lingkungan sekolah terdapat guru yang merupakan pengganti orang tua, teman bagaikan saudara, dan juga ada nilai dan norma yang harus dipatuhi di dalam lingkungan sosial sekolah. Siswa yang tidak dapat menyesuaikan diri dengan lingkungan sosial di sekolah, akan cenderung melakukan perilaku menyimpang seperti vandalisme.
Hasil penelitian ini menyatakan pelaku vandalisme pada siswa kelas VIII di SMP Negeri 14 Pontianak memiliki keluarga yang kurang harmonis dengan sumbangan pengaruhnya $24,7 \%$ signifikan dan memiliki hubungan sosial yang sangat rendah di lingkungan sekolah dengan pengaruh 12,2\% secara signifikan yang dapat diartikan bahwa siswa masih sangat rentan melakukan perilaku vandalisme, sehingga keluarga dan lingkungan sosial sekolah yang memiliki pengaruh dan kontribusi terhadap perilaku vandalisme diharapkan dapat lebih ditingkatkan agar perilaku vandalisme siswa menurun.

\section{SIMPULAN DAN SARAN Simpulan}

Perilaku vandalisme siswa kelas VIII SMP Negeri 14 Pontianak yang terpilih menjadi sampel dalam penelitian ini berada pada kategori cukup tinggi. Ciri yang menunjukkan perilaku vandalisme paling tinggi tampak pada perilaku graffity yaitu perilaku yang suka mencoret-coret sarana dan prasarana sekolah, dan destroying yaitu merusak fasilitas sekolah.

Terdapat pengaruh yang signifikan negatif antara keharmonisan keluarga terhadap perilaku vandalisme siswa kelas VIII SMP Negeri 14 Pontianak dengan nilai $\mathrm{t}_{\text {hitung }}-4,486>\mathrm{t}_{\text {tabel }} 1,982$. Nilai Sig. $0,00<$ taraf signifikansi 0,05 dan sumbangan pengaruh sebesar $24,7 \%$ yang artinya berkategori rendah dan terdapat pengaruh yang negatif dan signifikan antara lingkungan sosial sekolah terhadap perilaku vandalisme siswa kelas VIII SMP Negeri 14 Pontianak dengan nilai $t_{\text {hitung }}-2,547>t_{\text {tabel }}$ 1,982. Nilai Sig. 0,01 < taraf signifikansi 0,05 dan sumbangan pengaruh sebesar $12,2 \%$ (rendah). 
Hasil penelitian menunjukan bahwa adjusted $R$ Square yang diperoleh adalah sebesar 0,358 . Artinya sumbangan pengaruh keharmonisan keluarga dan lingkungan sosial sekolah terhadap perilaku vandalisme siswa kelas VIII SMP Negeri 14 Pontianak berkategori rendah yaitu sebesar 35,8\% dan $64,2 \%$ sisanya lebih kuat dipengaruhi oleh faktor-faktor lain selain keharmonisan keluarga dan lingkungan sosial sekolah.

Saran

Sebaiknya siswa tidak melakukan perilaku vandalisme karena perilaku tersebut merugikan lingkungan. Untuk itu, diharapkan siswa dapat mengalihkan kebiasaan perilaku vandalisme seperti membuat graffity pada media yang tepat.

Perlu adanya sosialisasi kepada masyarakat melalui media khususnya kepada keluarga agar dapat memberikan banyak perhatian dan membangun keluarga yang lebih harmonis agar dapat membentuk karakter anak yang positif dan terhindar dari perilaku menyimpang baik di rumah maupun di sekolah.

Sekolah perlu mencantumkan peraturan secara tertulis bahwa vandalisme termasuk salah satu pelanggaran yang harus dihindari untuk dilakukan. Sosialisasi dan sanksi yang tegas perlu dilakukan agar siswa mengetahui bahwa perilaku vandalisme termasuk salah satu perilaku menyimpang dan tidak boleh dilakukan.

Bagi peneliti selanjutnya, yang tertarik melanjutkan penelitian tentang vandalisme dapat menggabungkan metode penelitian kuantitatif dan kualitatif agar dapat meneliti lebih dalam mengenai perilaku vandalisme siswa di sekolah. Selain itu, diharapkan peneliti selanjutnya dapat menambah variabel lain yang diduga lebih kuat pengaruhnya terhadap perilaku vandalisme yang mana tidak diteliti pada penelitian ini.

\section{DAFTAR RUJUKAN}

Corene de Wet. (2004). The Extent and Causes of Learner Vandalism at Schools. Department of Comparative Education and Education Management. South African Journal of Education. Vol. 24 (3) 206-211.

Cummins .C. (2003). School vandalism not new, just more expensive. Report Card on Education. http://www.educationreportcard. com/columns/2003-01-12.

Faudah, N. (2006). Gambaran Kenakalan Siswa di SMA Muhammadiyah 4 Kendal. Jurnal Psikologi Media Ilmiah Psikologi. https://ejurnal.esaunggul.ac.id/in dex.php/psiko/article/view/1490

Masruri, K. (2011). Peranan SMA Negeri dalam Penanggulangan Aksi Vandalisme di Wilayah Kota Yogyakarta. Yogyakarta: Skripsi FISUNY.

Theron A. (1991). Vandalisme in kriminologiese perspektief. Acta Criminologica, 4:47-54.

Zuzile. M. (2003). Head shuts vandalized school. Dispatch Online, 24 July. url:http://www.dispatch.co.za/20 03/07/24/easterncape/aaaalead.h tm. 